\title{
Effect of Insertion Viscoelastic Damping Layer with Different Thicknesses on the Dynamic Response of Multi-layered Beam in Forced Vibration
}

\author{
Messaoud Baali*, Mohamed Nadir Amrane ${ }^{1}$ \\ ${ }^{1}$ Department of Mechanical Engineering, Faculty of Science and Technology, University of Biskra, 07000 Biskra, P. O. B. 145 RP, \\ Algeria \\ * Corresponding author, e-mail: benbaali@yahoo.fr
}

Received: 04 June 2017, Accepted: 16 October 2020, Published online: 11 November 2020

\begin{abstract}
In this work, we study the effect of the thickness variation of viscoelastic layer inserted in a laminated multi-layer beam in forced vibration on the vertical displacements and on the natural frequencies. The new structure is a sandwich structure composed by two external layers (top and bottom facesheets) of aluminum and viscoelastic core of 3M ISD112 polymers. The viscoelastic model used to describe the behavior of the core is a four-parameter fractional derivative model. The finite element method including the viscoelastic model of fractional derivatives for modeling the sandwich structure is used. The system resolution of the nonlinear equations of motion of the sandwich structure is required to use a numerical integration method as the explicit method of Newmark to obtain the transient response. Also, ANSYS finite element modeling is applied to the sandwich structure to calculate the frequency response in harmonic vibration. The increase in the thickness of the viscoelastic layer leads to a decrease in the amplitudes of vibration. The natural frequencies found by the two methods are very close to the frequencies found experimentally in the literature.
\end{abstract}

Keywords

sandwich beam, viscoelasticity, fractional derivatives, finite element method, forced vibration, ANSYS

\section{Introduction}

In recent years the research community has manifested a sound interest in the investigation of dynamic behavior of slightly damped structures [1-3]. Many researchers have shown that the employment of viscoelastic materials can improve the dynamics of such structures [4-7]. These materials can be incorporated into different types of structures by means of a number of methods and techniques $[8,9]$. According to Amrane [10] and Trindade [11], the passive vibration damping techniques structural systems use the integration or addition of materials to the structure to be damped without any additional external intervention, and the vibratory energy is dissipated in the form of heat. This is the principle of passive vibration control.

The use of the fractional derivative concept, in the context of viscoelasticity, was commonly applied as an effective technique for curve-fitting of experimental data [12-14]. Bagley and Torvik [15, 16] developed a one-dimensional model for a viscoelastic material using fractional derivative operators. Since then, this model for viscoelastic solids was incorporated in many structural applications as well as specific implementation of fractional constitutive models into computational procedures such as finite elements. Galucio et al. [17] developed a finite element formulation to analyze the transient dynamics of a sandwich beam with viscoelastic embedded layer whose material behavior was modeled with fractional derivative operators. They used the four-parameters model of Bagley and Torvik [15] to characterize the frequency-dependence of the viscoelastic layer.

This work presents a finite element modeling of a sandwich beam with a viscoelastic core (Fig. 1) in forced vibration. We used the fractional derivative model to describe

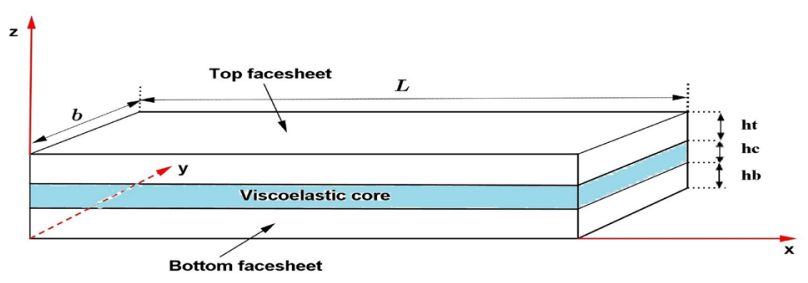

Fig. 1 Sandwich beam geometry 
the frequency dependence of the viscoelastic layer [17]. The Newmark explicit integration method is adopted to obtain the approximate numerical solution in the temporal domain of equations of motion [4, 17]. The algorithm of the Newmark method is already programmed in MATLAB to obtain the temporal response of the sandwich beam in transient vibration for different thicknesses of viscoelastic layer. Finally, another finite element modeling with ANSYS applied on the sandwich structure in free vibration to calculate the natural frequencies and harmonic vibration to calculate the frequency response.

\section{Fractional derivative viscoelastic model}

According to Bagley and Torvik [15], the one-dimensional constitutive equation used to describe the behavior of a viscoelastic material can be written as:

$$
\sigma(t)+\tau^{\alpha} \frac{d^{\alpha} \sigma(t)}{d t^{\alpha}}=E_{0} \varepsilon(t)+\tau^{\alpha} E_{\infty} \frac{d^{\alpha} \varepsilon(t)}{d t^{\alpha}},
$$

where $\sigma$ and $\varepsilon$ are the stress and the strain, $E_{0}$ and $E_{\infty}$ are the relaxed and non-relaxed elastic moduli, $\alpha$ is the fractional order of the time derivative and $\tau$ is the relaxation time.

After calculating the Fourier transform of Eq. (1), one obtains the expression of the complex modulus of elasticity for the four-parameter model $[14,15]$ :

$$
E^{*}=\frac{\sigma^{*}(\omega)}{\varepsilon^{*}(\omega)}=\frac{E_{0}+E_{\infty}(i \omega \tau)^{\alpha}}{1+(i \omega \tau)^{\alpha}},
$$

where $\sigma^{*}$ and $\varepsilon^{*}$ are the Fourier transforms of $\sigma(t)$ and $\varepsilon(t)$, respectively. Its behavior in the frequency domain is described between two asymptotic values: the static modulus of elasticity $E_{0}=E^{*}(\omega \rightarrow 0)$ and the high-frequency limit value of the dynamic modulus $E_{\infty}=E^{*}(\omega \rightarrow \infty)$. The statements $0<\alpha<1, \tau>0$ and $E_{\infty}>E_{0}$ must hold to fulfill the second law of thermodynamics.

The fractional operator derivative $d^{\alpha} /\left(d t^{\alpha}\right)$ appearing in the constitutive Eq. (1), is approximated by the GrünwaldLetnikov definition as [4]:

$$
\frac{d^{\alpha} f(t)}{d t^{\alpha}} \approx\left(\frac{t}{N}\right)^{-\alpha} \sum_{j=0}^{N_{t}} A_{j+1}^{(\alpha)} f\left(t-j \frac{t}{N}\right),
$$

where $\Delta t=t / N$ is the time step increment, $N_{t}$ is the maximum number of terms of the Grünwald approximation $\left(N_{t}<N\right)$, and $A_{j+1}^{(\alpha)}$ represents the Grünwald coefficients given either in terms of the gamma function or by the recurrence formulae:

$$
A_{j+1}^{(\alpha)}=\frac{\Gamma(j-\alpha)}{\Gamma(-\alpha) \Gamma(j+1)} \text { or } A_{j+1}^{(\alpha)}=\frac{j-\alpha-1}{j} A_{J}^{(\alpha)} .
$$

In order to avoid working with the stress history arising from the approximation of Eq. (1), let us introduce the following variable change $[4,17]$ :

$\bar{\varepsilon}(t)=\varepsilon(t)-\frac{\sigma(t)}{E_{\infty}}$,

such that the constitutive Eq. (1) can be rewritten in a discretized form as [17]:

$\bar{\varepsilon}(t)+\tau^{\alpha} \frac{d^{\alpha} \bar{\varepsilon}(t)}{d t^{\alpha}}=\frac{E_{\infty}-E_{0}}{E_{\infty}} \varepsilon(t)$.

This change of the strain variable leads to the presence of only one fractional derivative operator in the constitutive expression of Eq. (6) instead of the two fractional operators in Eq. (1). Using the Grünwald approximations, by substituting Eq. (3) in Eq. (6), and taking into account that $A_{1}=1$, it is possible to arrive to the following discretized form of the constitutive relation $[4,17]$ :

$$
\begin{aligned}
& \bar{\varepsilon}(t+\Delta t)=(1-c) \frac{E_{\infty}-E_{0}}{E_{\infty}} \varepsilon(t+\Delta t) \\
& -c \sum_{j=1}^{N_{t}} A_{j+1}^{(\alpha)} \bar{\varepsilon}(t+\Delta t-j \Delta t),
\end{aligned}
$$

where $c$ is a dimensionless constant given by:

$$
c=\frac{\tau^{\alpha}}{\tau^{\alpha}+(\Delta t)^{\alpha}} \text {. }
$$

It should be stated that the Grünwald coefficients in Eq. (7), which are strictly decreasing when $j$ increases, describe the fading memory phenomena. In another words, the behavior of the viscoelastic material at a given time step depends more strongly on the recent time history than on the distant one [17].

\section{Finite element modeling of the viscoelastic sandwich beam}

\subsection{Modeling by finite element with incorporation of the fractional derivative model}

The implementation of the constitutive relation of the viscoelastic material provided by Eq. (7) in the context of finite elements is developed in the works of Galucio et al. [17], Faria [4] for purely viscoelastic structures or composite sandwiches. At the elementary level, the incorporation of viscoelastic behavior into the finite element formulation results in Eq. (9) of motion [4, 17]:

$$
\begin{aligned}
& {\left[M_{e}\right]\left\{\ddot{u}_{e}(t+\Delta t)\right\}+\left[\left[K_{e}\right]+\left[\tilde{K}_{e}^{v}\right]\right]\left\{u_{e}(t+\Delta t)\right\}} \\
& =\left\{F_{e}(t+\Delta t)\right\}+\left\{\tilde{\boldsymbol{F}}_{\boldsymbol{e}}^{v}(\boldsymbol{t}+\Delta \boldsymbol{t})\right\},
\end{aligned}
$$


where the element mass matrix:

$$
\left[M_{e}\right]=\left[M_{e}^{t}\right]+\left[M_{e}^{b}\right]+\left[M_{e}^{v}\right] \text {, }
$$

and the element stiffness matrix:

$$
\left[K_{e}\right]=\left[K_{e}^{t}\right]+\left[K_{e}^{b}\right]+\left[K_{e}^{v}\right] .
$$

With the modified stiffness matrix $\left[\tilde{K}_{e}^{v}\right]$ and loading vector $\left\{\tilde{\boldsymbol{F}}_{\boldsymbol{e}}^{v}(\boldsymbol{t}+\Delta \boldsymbol{t})\right\}$, arising from the viscoelastic behavior of the core, are given by:

$$
\begin{aligned}
& {\left[\tilde{K}_{e}^{v}\right]=c \frac{E_{\infty}-E_{0}}{E_{0}}\left[K_{e}^{v}\right],} \\
& \left\{\tilde{\boldsymbol{F}}_{\boldsymbol{e}}^{v}(\boldsymbol{t}+\Delta \boldsymbol{t})\right\}=-c \frac{E_{\infty}}{E_{0}}\left[K_{e}^{v}\right] \sum_{j=1}^{N_{t}} A_{j+1}^{(\alpha)}\left\{\bar{u}_{e}(t+d t-j \Delta t)\right\} .
\end{aligned}
$$

In Eq. (9) the terms written as a function of the history provided by Eq. (13) are located in the right hand side.

At the global level, the equation of motion of the damped system including the viscoelastic model of fractional derivatives is given by [4]:

$\left[\bar{M}_{g}\right]\left\{\ddot{u}_{g}(t)\right\}+\left[\bar{K}_{g}(t)\right]\left\{\boldsymbol{u}_{g}(\boldsymbol{t})\right\}=\left\{\overline{\boldsymbol{F}}_{g}(\boldsymbol{t})\right\}$,

where $\left[\bar{M}_{g}\right],\left[\bar{K}_{g}(t)\right]$ and $\left\{\overline{\boldsymbol{F}}_{g}(\boldsymbol{t})\right\}$ symbolize the global mass matrix, stiffness matrix, is the global loading vector, respectively. $\left\{\boldsymbol{u}_{\boldsymbol{g}}(\boldsymbol{t})\right\}$ is the global vector of degrees of freedom.

The Newmark time-integration method is employed to solve the global system governing nonlinear equations of motion (Eq. (14)), whose the nonlinearity is present in the matrices of stiffness $\left[\bar{K}_{g}(t)\right]$ and in the vector $\left\{\overline{\boldsymbol{F}}_{\boldsymbol{g}}(\boldsymbol{t})\right\}$ depending on time and temperature. The algorithm of Newmark explicit numerical integration applied in this work to the dynamic study (transient responses) of sandwich structures is presented in much publications such as Faria [4] and Galucio et al. [17], the classical Newmark algorithm is modified to have a new parameter for the storage of the anelastic displacement history.

\subsection{Modeling by finite element of ANSYS Parametric Design Language (APDL)}

The ANSYS 12.0 finite element software package is used to model the multi-layered beam structure with integral damping layer [18-20]. In this case, the facesheets (elastic layers) are modeled using shell element SHELL281, which has 8 nodes with six degrees of freedom at each node. While solid brick element SOLID186 are used for modeling the viscoelastic core, is defined by 20 nodes having three degrees of freedom per node: translations in the nodal $x, y$, and $z$ directions [19]. Fig. 2 shows the schematic of the sandwich beam model.

The shell elements by default place the nodes at the midplane of the top and the bottom facesheets. if the nodes of the shell elements were shared with the solid brick element, half of the facesheets element in the thickness direction would penetrate into the solid brick element [18]. Fig. 3 shows the enlarged view of the sandwich beam under ANSYS using the shell element SHELL281 (denoted by 1) to model the facesheets and the solid brick element SOLID186 (denoted by 2) to model the viscoelastic core.

For coupling the degree of freedom of shell elements SHELL281 with the degree of freedom of solid brick elements SOLID186, we used the rigid constraint equations command CERIG developed in APDL (Fig. 4) [19].

In ANSYS the Prony series is widely used for the analytical representation of functions characterizing viscoelastic materials. The complex shear modulus based on the generalized standard model in the frequency domain for $N$ terms can be written as [9]:

$G(\omega)=G_{0}\left[1-\sum_{n=1}^{N} g_{n}+\sum_{n=1}^{N} \frac{i \omega g_{n} \tau_{n}}{1+i \omega \tau_{n}}\right]$,

with $\tau_{n}$ relaxation times, $g_{n}$ relative moduli, $\omega$ is frequency, $N$ number of terms and $G_{0}$ is the instantaneous shear modulus.
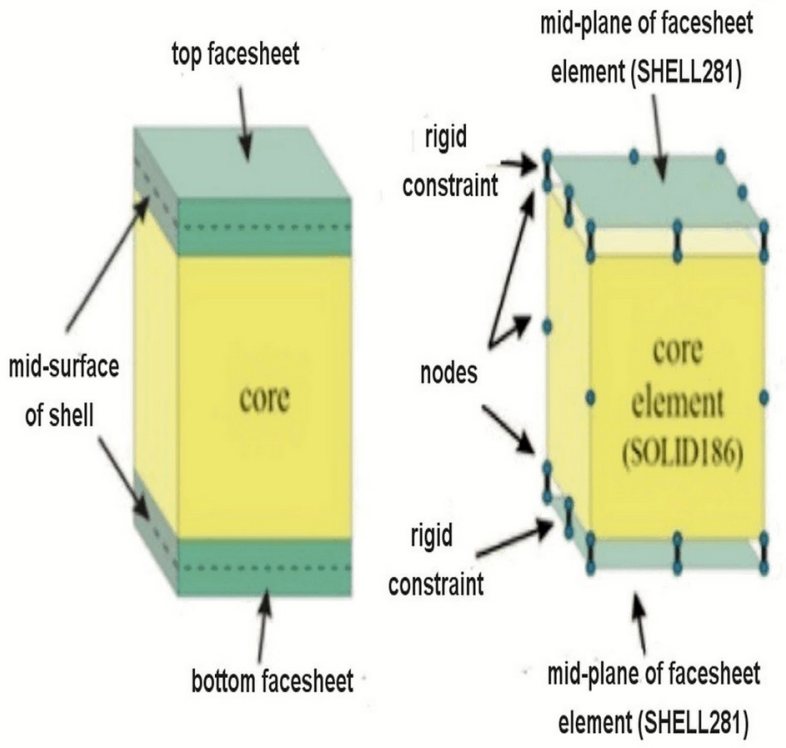

Fig. 2 A sandwich beam and corresponding finite element model utilizing rigid constraints between the shell and solid elements [18, 19] 


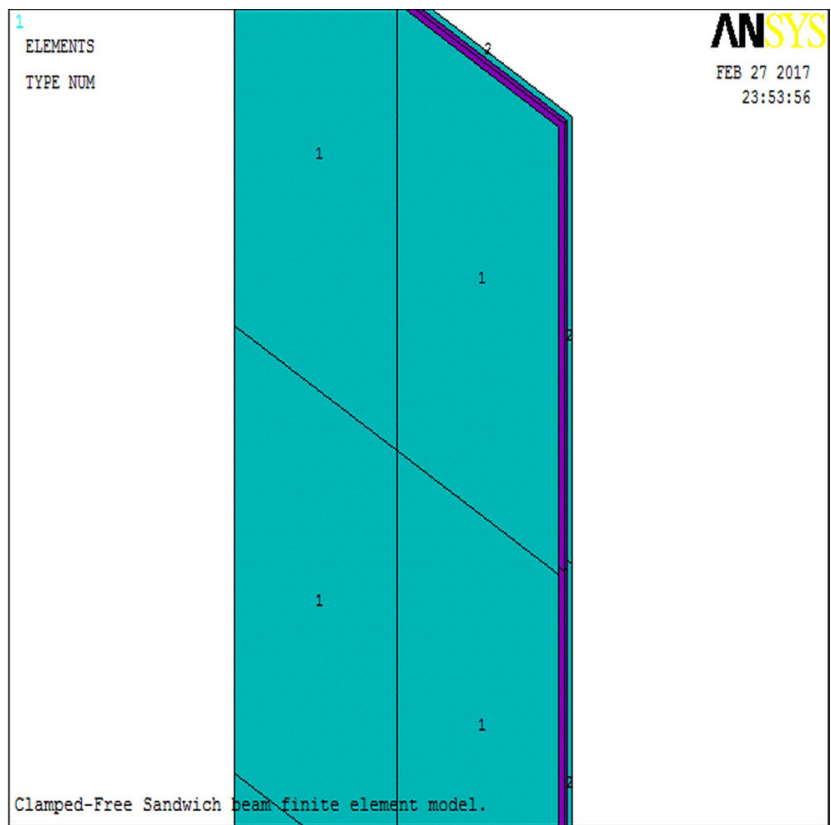

Fig. 3 The finite element model of the sandwich beam in ANSYS representing the two different element types used

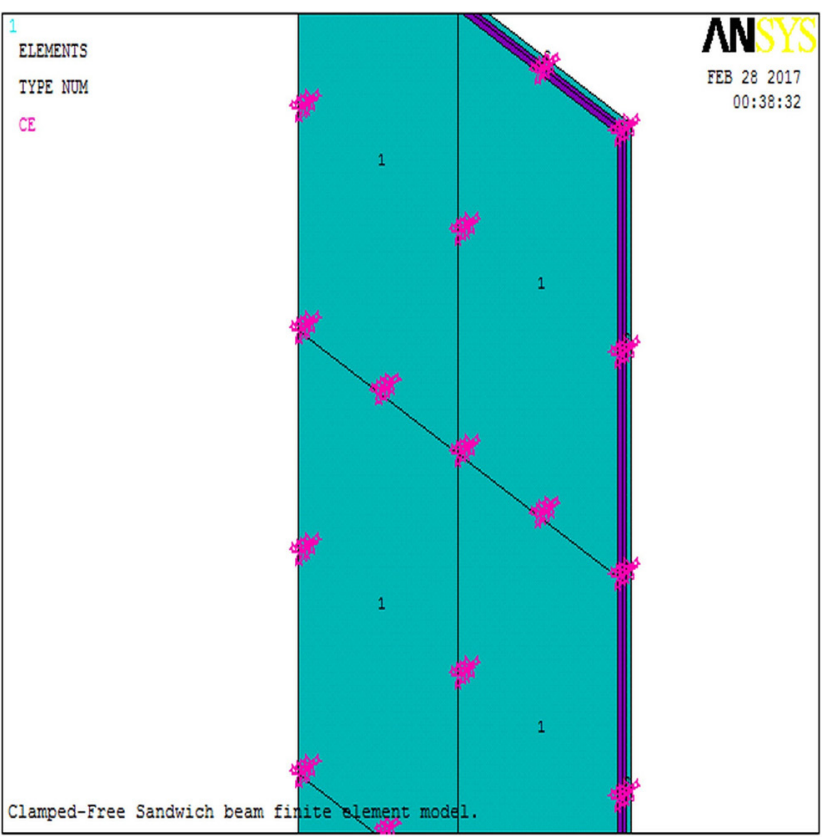

Fig. 4 The constraints relating the motion of the facesheets to the motion of core under ANSYS

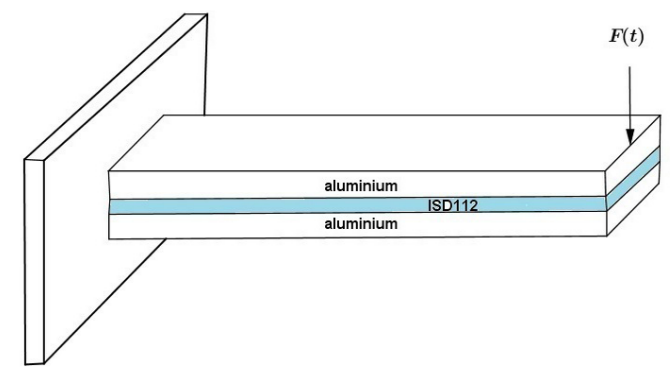

\section{Numerical application}

In this application, we use a cantilevered sandwich beam with viscoelastic core (3M ISD112 polymer at $27^{\circ} \mathrm{C}$ ) and symmetrical elastic faces (aluminum). The geometrical parameters of the beam are: length $L=457.2 \mathrm{~mm}$, width $b=25.4 \mathrm{~mm}$, thickness of top and bottom face sheets $h_{t}=h_{b}=0.794 \mathrm{~mm}$ and thickness of core $h_{c}$ varies between $0.051,0.127$ and $0.254 \mathrm{~mm}[8,11]$.

\subsection{Application with using the finite element modeling incorporating the fractional derivative model}

The structure is discretized using the finite elements formulated by Faria [4], whose model consists of $6 \times 1$ finite elements. The beam in free vibration is needed to calculate natural frequencies, and the transient vibration to calculate the temporal response function.

The beam is subjected to a transverse load, applied at the free end as a triangular impulse form for $4 \mathrm{~ms}$ and then released, as shown in Fig. 5. The observation time is $5 \mathrm{~s}$.

The parameters of the fractional derivative model are: $\alpha=0.7915$ and $\tau=1.40 \times 10^{-2} \mathrm{~ms}$. The mechanical properties of the elastic aluminum faces and the viscoelastic core are tabulated in Table 1.

The time step is taken from the example as $\Delta t=1 \mathrm{~ms}$ and the number of terms in the Grünwald approximation $N_{t}=5000$. The transient response is computed with the implicit time integration scheme described in numerous publications such as Faria [4] and Galucio et al. [17].

The first three natural frequencies, shown in Table 2, are calculated for the three thicknesses of the viscoelastic layer $\left(h_{c}=0.254,0.127\right.$ and $0.051 \mathrm{~mm}$ ) by using the finite element modeling incorporate the fractional derivative model [4]. The results are then compared with those calculated by the finite element method and experimental tests presented in $[8,11]$.

The results of natural frequencies obtained by this model are very close to the experimental results of Wang and Wereley [8], and are very close to finite element method results of Trindade [11]. It can be seen that

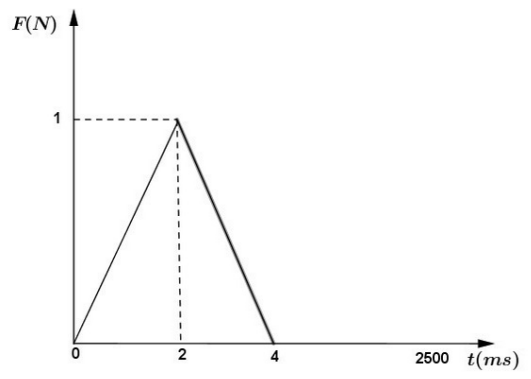

Fig. 5 Sandwich cantilever beam is subjected to a triangular impulse load 
Table 1 Material properties of visco-aluminum sandwich beam [11, 17]

\begin{tabular}{lclc}
\hline \multicolumn{2}{c}{ Face sheets } & \multicolumn{2}{c}{ Viscoelastic core } \\
\hline Property & Aluminum & Property & $\begin{array}{c}\text { ISD112 } \\
\left.\text { (at } 27^{\circ} \mathrm{C}\right)\end{array}$ \\
$E(\mathrm{GPa})$ & 75.8 & $E_{0}(\mathrm{GPa})$ & 1.5 \\
$v$ & 0.3 & $E_{\infty}(\mathrm{GPa})$ & 69.9495 \\
$\rho\left(\mathrm{kg} / \mathrm{m}^{3}\right)$ & 2800 & $\rho\left(\mathrm{kg} / \mathrm{m}^{3}\right)$ & 0.5 \\
\hline
\end{tabular}

Table 2 Natural frequencies $(\mathrm{Hz})$ of the sandwich beam has different thicknesses of the viscoelastic layer

\begin{tabular}{|c|c|c|c|c|}
\hline Modes & $\begin{array}{c}\text { MEF } \\
{[\text { Present work] }} \\
\text { Freq }(\mathrm{Hz})\end{array}$ & $\begin{array}{c}\text { ANSYS } \\
{[\text { Present work] }} \\
\text { Freq }(\mathrm{Hz})\end{array}$ & $\begin{array}{c}\text { Experimental } \\
{[8]} \\
\text { Freq }(\mathrm{Hz})\end{array}$ & $\begin{array}{c}\text { MEF } \\
{[11]} \\
\text { Freq } \\
(\mathrm{Hz})\end{array}$ \\
\hline \multicolumn{5}{|c|}{ Viscoelastic layer to $0.051 \mathrm{~mm}$} \\
\hline 1 & 5.93 & 6.34 & 6.64 & 6.90 \\
\hline 2 & 38.03 & 39.45 & 36.21 & 39.27 \\
\hline 3 & 110.96 & 96.56 & 85.23 & 103.30 \\
\hline \multicolumn{5}{|c|}{ Viscoelastic layer to $0.127 \mathrm{~mm}$} \\
\hline 1 & 6.03 & 6.68 & 6.84 & 7.05 \\
\hline 2 & 38.07 & 41.11 & 35.62 & 36.62 \\
\hline 3 & 109.22 & 95.29 & 92.42 & 92.25 \\
\hline \multicolumn{5}{|c|}{ Viscoelastic layer to $0.254 \mathrm{~mm}$} \\
\hline 1 & 6.20 & 7.24 & 7.22 & 7.30 \\
\hline 2 & 38.18 & 43.76 & 36.79 & 34.62 \\
\hline 3 & 107.43 & 93.27 & 89.50 & 84.66 \\
\hline
\end{tabular}

by increasing thickness of viscoelastic damping layer $h_{c}$, natural frequencies are increased.

The transverse displacement (the transient response) of the cantilevered sandwich beam is shown in Fig. 6 for the three different thicknesses of the viscoelastic layer $h_{c}$. We note that the increase in the thickness of the viscoelastic layer leads to the decrease of the response (the amplitudes of vibration).

\subsection{Application with using ANSYS}

The meshing of the viscoelastic sandwich beam involves 2 elements through the width and 20 elements along the length (Fig. 7). Material constants for aluminum facesheets are listed in Table 3. The viscoelastic damping material used is 3M ISD112, and represented by Prony series constants are listed in Table 4, where shear modulus and loss factor are dependent on frequency and temperature.

Modal analysis is carried out using the Block Lanczos method of ANSYS for finding the natural frequencies and mode shapes. The fixed free boundary condition was applied by constraining the nodal displacements in both $x$ and $z$ directions (Fig. 7).

Harmonic analysis is used to calculate the Frequency Response Functions (FRFs) with different thicknesses of damping layer by applying a harmonic load (with magnitude equal 10 Newton) at the end of the beam (point $\mathrm{P}$, DOF of translation $u_{z}$ ) as shown in Fig. 8. The frequency of the load varies from $1 \mathrm{~Hz}$ to $300 \mathrm{~Hz}$. The full ANSYS APDL method is used for this analysis.

The first three eigenmodes and eigenfrequencies are listed in Table 2, and the First four mode shapes are shown in Fig. 9. The natural frequencies obtained by finite element ANSYS modeling are very close to the experimental results of Wang and Wereley [8].

Fig. 10 shows the frequency responses of multi-layered beam with and without damping layer plotted for point $\mathrm{P}$ in the frequency band of interest [0-300] Hz, where the insertion of viscoelastic damping layer in multi-layered beam leads to the decrease of the frequency response.

The Frequency Response Functions (FRFs) of multilayered beam with different thicknesses of damping layer $\left(h_{c}=0.127\right.$ and $0.254 \mathrm{~mm}$ ) are shown in Fig. 11.

The increase in the thickness of the viscoelastic damping layer leads to the decrease of the frequency response of sandwich beam (the amplitudes of vibration).

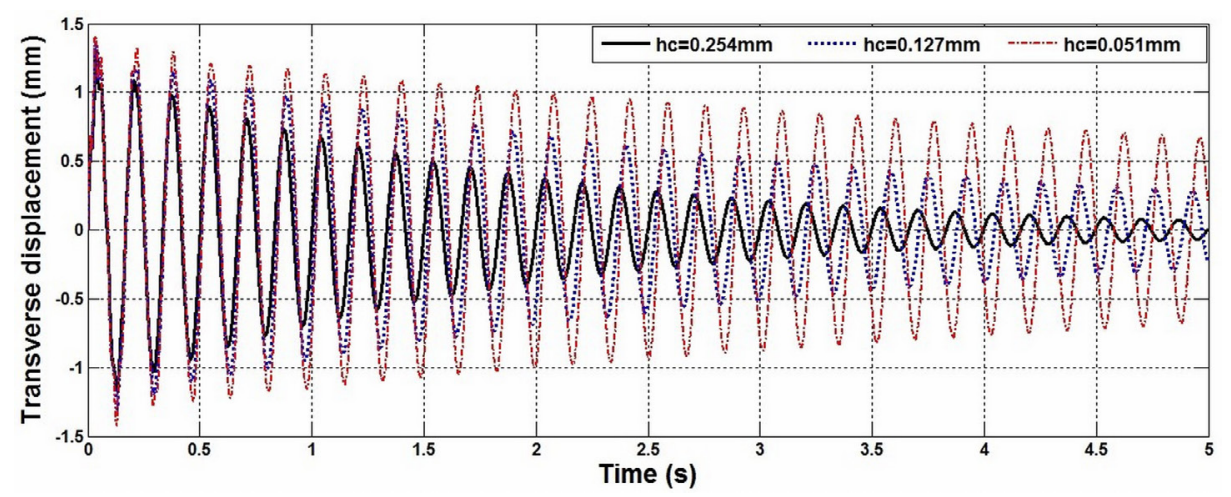

Fig. 6 Transient response of fractional derivative model of the sandwich beam with different $h_{c}$ 


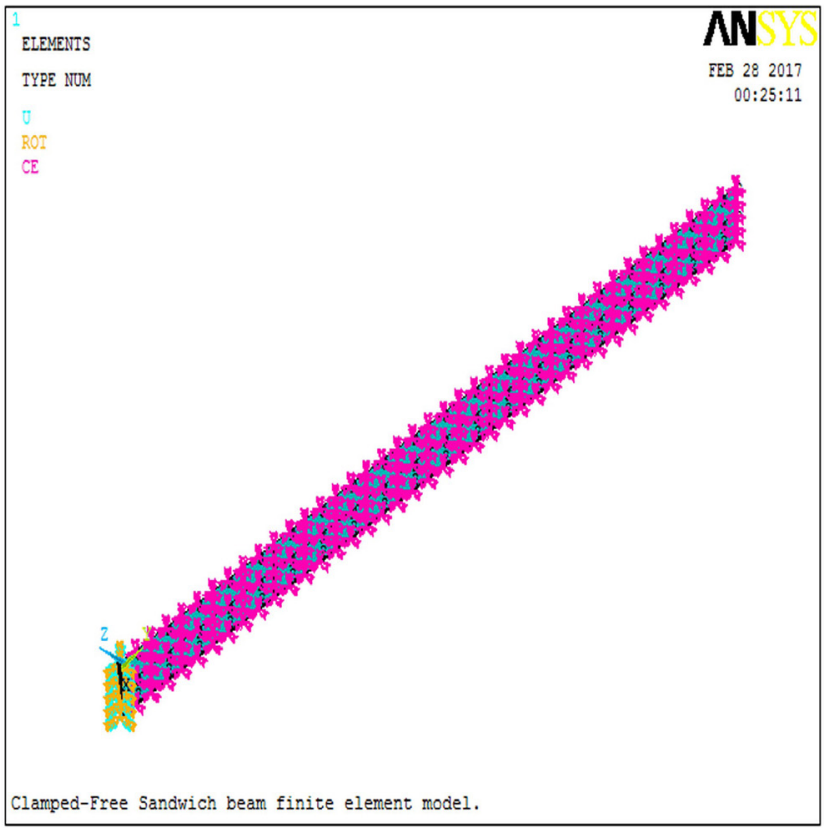

Fig. 7 Clamped-free sandwich beam finite element model (meshing, constraints relating and boundary conditions)

Table 3 Material properties of facesheets [8, 17]

\begin{tabular}{lc}
\hline Property & Aluminum facesheet \\
\hline Young modulus $E(\mathrm{GPa})$ & 69 \\
Density $\rho\left(\mathrm{kg} / \mathrm{m}^{3}\right)$ & 2800 \\
Poisson ratio $v$ & 0.345 \\
\hline
\end{tabular}

Table 4 3M ISD112 Material parameters required for Prony series expressions at room temperature with $N=8$ and $G_{0}=173 \mathrm{e} 6 \mathrm{~Pa}$,

\begin{tabular}{lcc}
\multicolumn{3}{c}{$v_{c}=0.499, \rho_{c}=1600 \mathrm{~kg} / \mathrm{m}^{3}[9]$} \\
\hline $1_{n}$ & $\tau_{n}\left(\mathrm{~s}^{-1}\right)$ \\
\hline $1^{\text {st }}$ Term & $3.103 \mathrm{e}-3$ & 0.6073 \\
$2^{\text {nd }}$ Term & $6.900 \mathrm{e}-3$ & 0.1511 \\
$3^{\text {rd }}$ Term & $1.231 \mathrm{e}-2$ & $3.038 \mathrm{e}-2$ \\
$4^{\text {th }}$ Term & $3.534 \mathrm{e}-2$ & $8.172 \mathrm{e}-3$ \\
$5^{\text {th }}$ Term & $6.562 \mathrm{e}-2$ & $1.821 \mathrm{e}-3$ \\
$6^{\text {th }}$ Term & 0.1541 & $4.810 \mathrm{e}-4$ \\
$7^{\text {th }}$ Term & 0.2612 & $1.201 \mathrm{e}-4$ \\
$8^{\text {th }}$ Term & 0.4540 & $3.014 \mathrm{e}-5$ \\
\hline
\end{tabular}

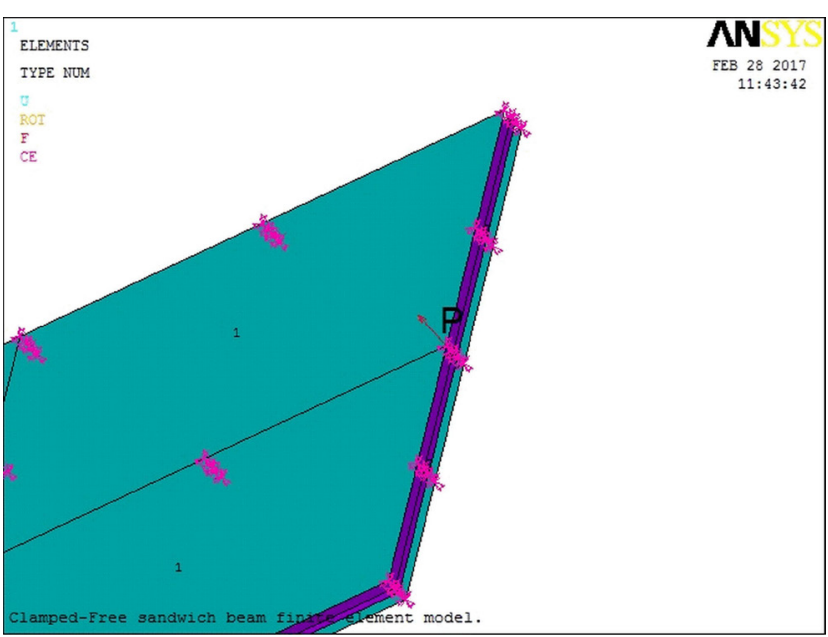

Fig. 8 Applying the excitation load in the extremity of the sandwich beam (point $\mathrm{P}$ )

\section{Conclusion}

In the present work, a finite element modeling of a viscoelastic core sandwich beam in transient vibration is performed. The fractional derivative model DF to describe the frequency dependence of the viscoelastic layer is used. The Newmark time-integration scheme is used to solve the assembled global equation of motion in the time domain to obtain the transient response of the beam. A finite element modal analysis with ANSYS is adopted to compute the natural frequencies and harmonic frequency responses.

The numerical application shows that the increase in the thickness of the viscoelastic layer inserted into the multi-layered beam leads to a decrease in the amplitudes of vibration and small increase in the natural frequencies due to the damping properties of this embedded layer. These properties coupled to the structure (the multi-layered beam) in such way the vibrations are damped passively (passive vibration control). 


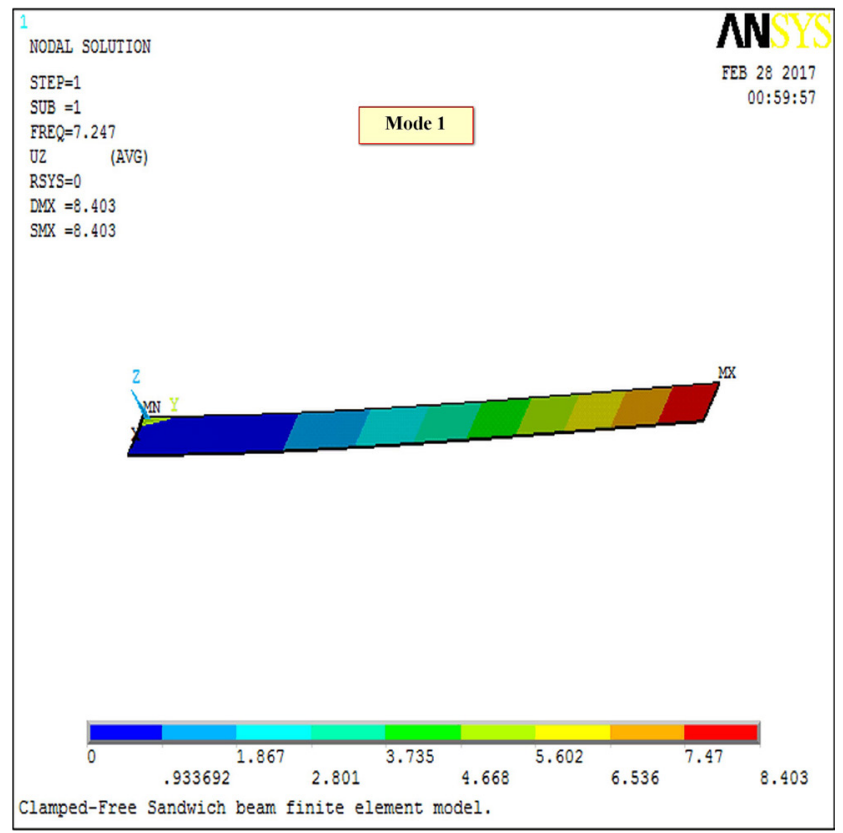

(a)

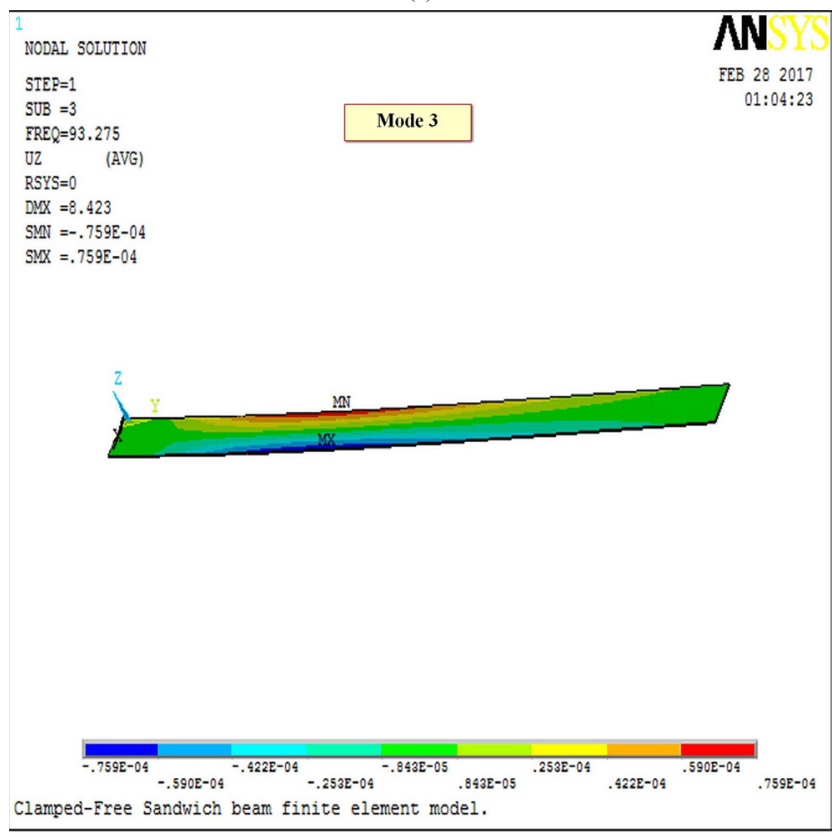

(c)

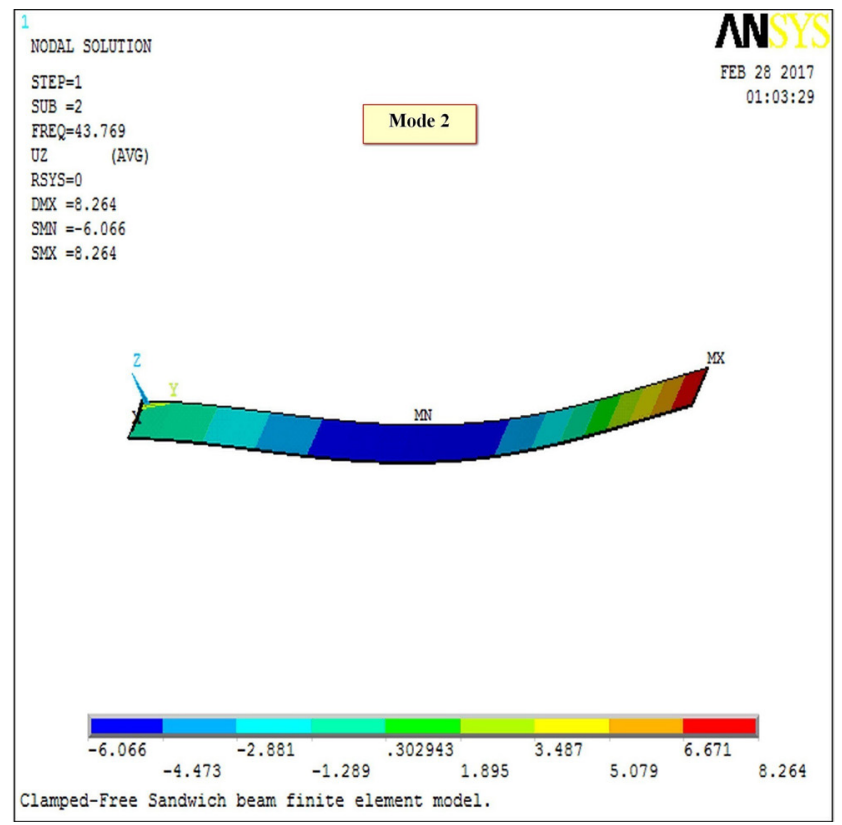

(b)

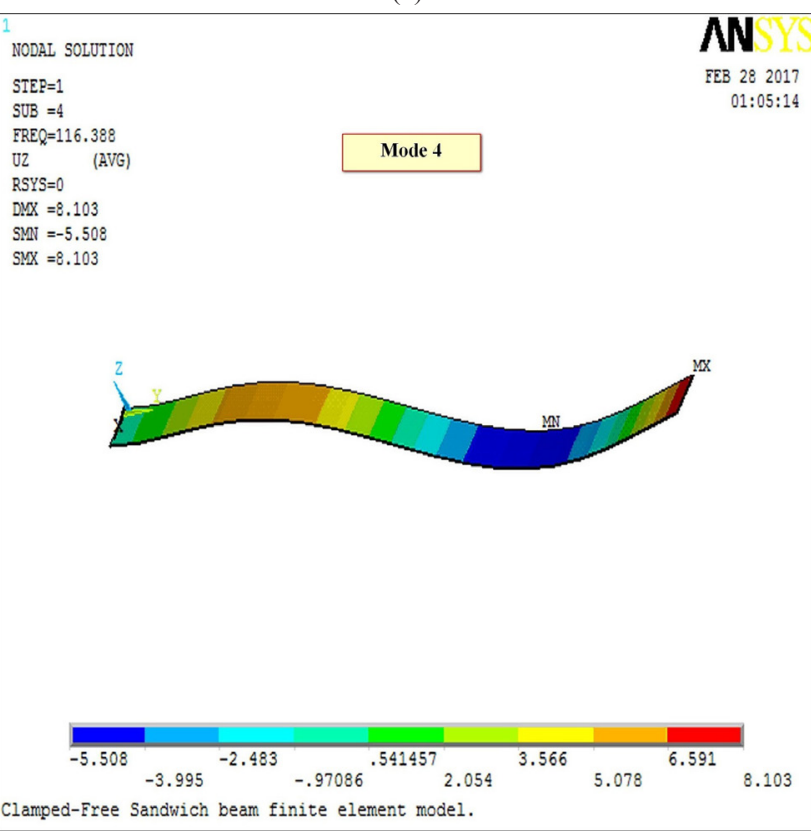

(d)

Fig. 9 The first four mode shapes of the clamped-free sandwich beam (for $h_{c}=0.254 \mathrm{~mm}$ ) 


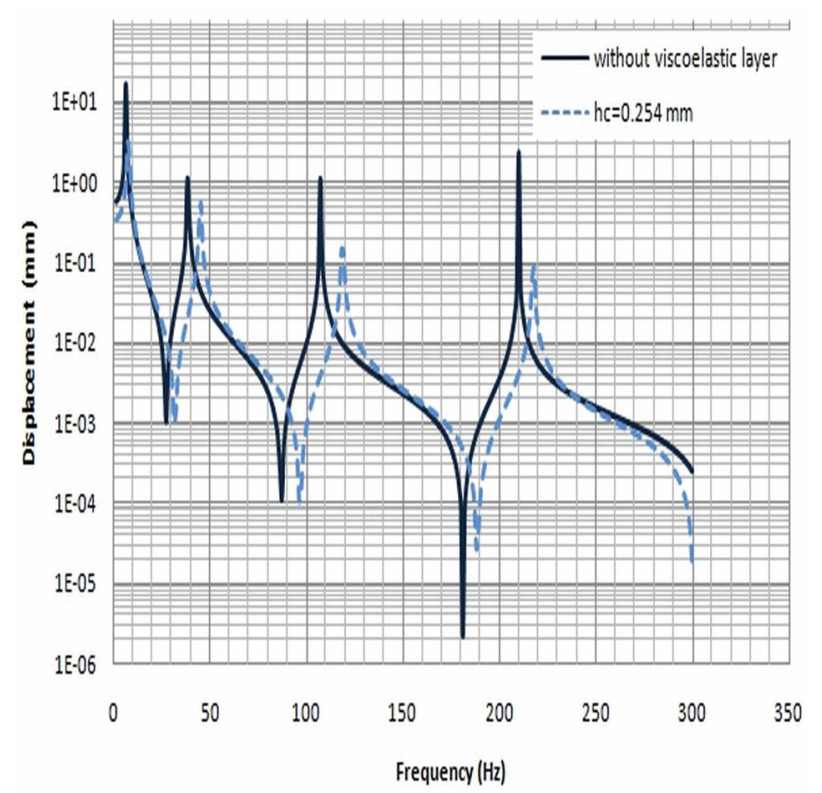

Fig. 10 FRFs at point $P$ of multi-layered beam with and without damping layer

\section{References}

[1] Roderic, L. "Viscoelastic Materials", Cambridge University Press, New York, NY, USA, 2009.

[2] Huang, Z., Qin, Z., Chu, F. "Vibration and damping characteristics of sandwich plates with viscoelastic core", Journal of Vibration and Control, 22(7), pp. 1876-1888, 2016.

https://doi.org/10.1177/1077546314545527

[3] Barkanov, E., Rikards, R., Holste, C., Täger, O. "Transient response of sandwich viscoelastic beams, plates, and shells under impulse loading", Mechanics of Composite Materials, 36(3), pp. 215-222, 2000. https://doi.org/10.1007/BF02681873

[4] Faria, A. W. "Modélisation par éléments finis de plaques composites: contribution a l'étude de l'amortissement, endommagement et prise en compte d'incertitudes" (Finite element modeling of composite plates: contribution to the study of damping, damage and taking into consideration uncertainties), PhD Thesis, Federal University of Uberlândia, 2010. (in French) [online] Available at: https://repositorio.ufu.br/bitstream/123456789/14696/1/Tese\%20 Albert.pdf [Accessed: 20 February 2016]

[5] Piovan, M. T., Sampaio, R., Deü, J. F. "Dynamics of Sandwich Curved Beams with Viscoelastic Core Described by Fractional Derivative Operators", Computational Mechanics, XXVIII, pp. 691-710, 2009. [online] Available at: http://www.cimec.org.ar/ojs/index.php/ mc/article/viewFile/2765/2705 [Accessed: 20 May 2016]

[6] Zghal, S., Bouazizi, M. L., Bouhaddi, N., Nasri, R. "Model reduction methods for viscoelastic sandwich structures in frequency and time domains", Finite Elements in Analysis and Design, 93, pp. 12-29, 2015.

https://doi.org/10.1016/j.finel.2014.08.003

[7] Syed, R. U. H., Sabir, M. I., Wei, J., Shi, D. Y. "Effect of Viscoelastic Material Thickness of Damping Treatment Behavior on Gearbox", Research Journal of Applied Sciences, Engineering and Technology, 4(17), pp. 3130-3136, 2012. [online] Available at: http://maxwellsci. com/print/rjaset/v4-3130-3136.pdf [Accessed: 20 May 2016]

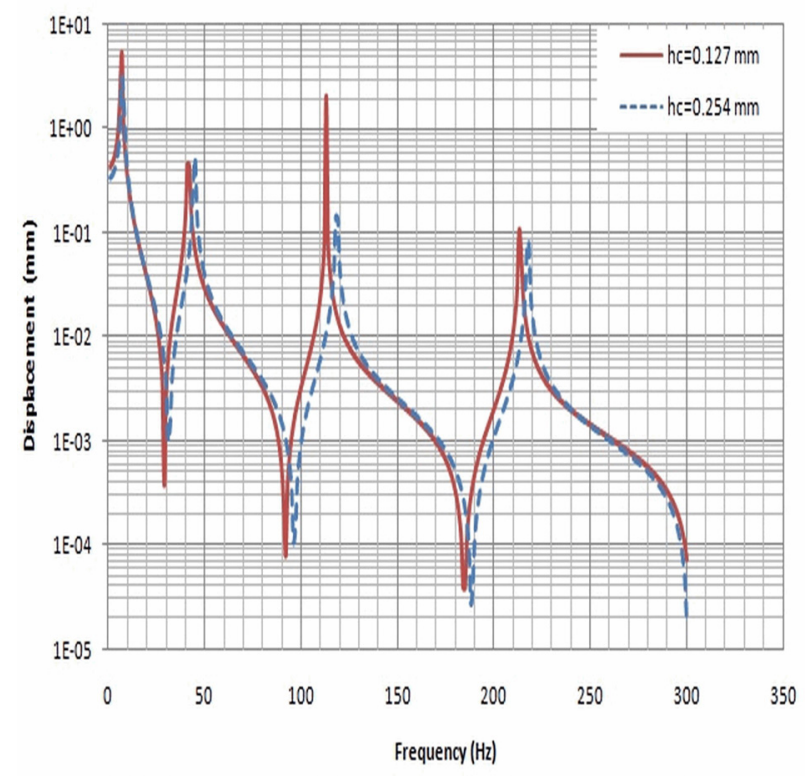

Fig. 11 FRFs at point $P$ of sandwich beam with different thicknesses of damping layer

[8] Wang, G., Wereley, N. M. "Frequency response of beams with passively constrained damping layers and piezoactuators", In: 5th Annual International Symposium on Smart Structures and Materials 1998: Passive Damping and Isolation Conference, San Diego, CA, USA, 1998, pp. 44-60.

https://doi.org/10.1117/12.310712

[9] Slanik, M. L., Nemes,J. A, Potvin, M. J., Piedboeuf, J. C. "Time Domain Finite Element Simulations of Damped Multilayered Beams Using a Prony Series Representation", Mechanics of TimeDependent Materials, 4(3), pp. 211-230, 2000. https://doi.org/10.1023/A:1009826923983

[10] Amrane, M. N. "Contrôle passif et actif des structures planes" (Passive and active control of plane structures), PhD Thesis, Ecole Centrale de Lyon, 1993. (in French)

[11] Trindade, M. A. "Contrôle hybride actif-passif des vibrations de structures par des matériaux piézoélectriques et viscoélastiques: poutres sandwich/multicouches intelligentes" (Hybrid activepassive control of structural vibrations by piezoelectric and viscoelastic materials: intelligent sandwich/multi-layer beams), PhD Thesis, National Conservatory of Arts and Crafts, 2000. [online] Available at: https://tel.archives-ouvertes.fr/tel-00012077/ document [Accessed: 15 March 2016] (in French)

[12] Cortés, F., Elejabarrieta, M. J. "Finite element formulations for transient dynamic analysis in structural systems with viscoelastic treatments containing fractional derivative models", International Journal for Numerical Methods in Engineering, 69(10), pp. 2173-2195, 2007.

https://doi.org/10.1002/nme.1840

[13] Galucio, A. C., Deu, J. F., Ohayon, R. "A Fractional Derivative Viscoelastic Model for Hybrid Active-Passive Damping Treatments in Time Domain - Application to Sandwich Beams", Journal of Intelligent Material Systems and Structures, 16(1), pp. 33-45, 2005 https://doi.org/10.1177/1045389X05046685 
[14] Pritz, T. "Analysis of Four-parameter Fractional Derivative Model of Real Solid Materials", Journal of Sound and Vibration, 195(1), pp. 103-115, 1996.

https://doi.org/10.1006/jsvi.1996.0406

[15] Bagley, R. L., Torvik, P. J. "Fractional Calculus - A Different Approach to the Analysis of Viscoelastically Damped Structures", AIAA Journal, 21(5), pp. 741-748, 1983. https://doi.org/10.2514/3.8142

[16] Bagley, R. L., Torvik, P. J. "Fractional Calculus in the Transient Analysis of Viscoelastically Damped Structures", AIAA Journal, 23(6), pp. 918-925, 1985. https://doi.org/10.2514/3.9007

[17] Galucio, A. C., Deü, J. F., Ohayon, R. "Finite element formulation of viscoelastic sandwich beams using fractional derivative operators", Computational Mechanics, 33(4), pp. 282-291, 2004.

https://doi.org/10.1007/s00466-003-0529-x
[18] Malekzadeh, K., Sayyidmousavi, A. "Free Vibration Analysis of Sandwich Plates with a Uniformly Distributed Attached Mass, Flexible Core, and Different Boundary Conditions", Journal of Sandwich Structures \& Materials, 12(6), pp. 709-732, 2010. https://doi.org/10.1177/1099636209343383

[19] Madenci, E., Guven, I. "The Finite Element Method and Applications in Engineering Using ANSYS ${ }^{\circledR}$, , Springer US, New York, NY, USA, 2015.

https://doi.org/10.1007/978-1-4899-7550-8

[20] Zhang, S. H., Chen, H. L. "A study on the damping characteristics of laminated composites with integral viscoelastic layers", Composites Structures, 74(1), pp. 63-69, 2006.

https://doi.org/10.1016/j.compstruct.2005.03.008 